\title{
«КРЕАТИВНЫЙ КЛАСС» В РАЗРЕЗЕ Р. ФЛОРИДЫ: ТОВАР ИННОВАЦИОННОЙ ЭКОНОМИКИ
}

\section{"CREATIVE CLASS" IN THE SECTION OF R. FLORIDA: PRODUCT OF INNOVATIVE ECONOMY}

\section{N. Krivovyaz}

Summary: The axial direction of evolution turned out to be determined by theoretical knowledge - it took priority positions, transforming status features, nature and character power and management. Large-scale application of knowledge turned the Western economy into an innovative economy, power has lost its potential, direct violence has been replaced by its hidden forms, and power based on wealth and strength has given way to the power of knowledge. In the conditions of development of an innovative economy, creativity becomes a product. Various authors were concerned about this issue, their approaches were different and the interpretation of the concept of "creative class" given by R. Florida was also considered in a different context by P. Drucker and J. Schumpeter. The approaches presented by the authors reinforce interpretations of a cognitive society permeated by the ethos of creativity, suggesting that building a knowledge economy without using the potential of the creative is impossible.

Keywords: creative class, fund, creativity, creative ethos, cognitive society, creative personality.

\author{
Кривовяз Наталья Викторовна \\ Ассистент, Национальный исследовательский Томский \\ политехнический университет \\ awatanchik@yandex.ru
}

Аннотация: Осевое направление эволюции оказалось определяемым теоретическим знанием, - оно, используемое в процедурах кодификации в системах символов, в процедурах интерпретации сфер опыта, используемое в процессах создания интеллектуальных технологий, применяемое в алгоритмах принимаемых решений, вышло на приоритетные позиции, трансформировав статусные особенности, роль, природу и характер власти и управления. В условиях масштабного применения знания, превратившего западную экономику в экономику инновационную, власть силы утратила свой потенциал, на смену прямому насилию пришли его скрытые формы, а власть, основанная на богатстве и силе, уступила место власти знания. В условиях развития инновационной экономики именно креативность, являясь капиталом, становится товаром. Данным вопросом были озабочены различные авторы, подходы которых были разными и трактовка понятия «креативный класс», данная Р. Флоридой, была рассмотрена в другом разрезе также П. Друкером и Й. Шумпетером. Подходы, излагаемые авторами, подкрепляют трактовки о когнитивном обществе, пронизанном этосом креативности, говорят о том, что построение экономики знания (креативной, инновационной экономики) без использования потенциала креативных невозможно.

Ключевые слова: креативный класс, капитал, креативность, креативный этос, когнитивное общество, креативная личность.

ние для того, чтобы назвать инновации «креативным разрушителем», что и сделал Й. Шумпетер, экономист и социолог в тех трудах, где дана интерпретация динамики экономических циклов, а сама цикличность представлена в качестве закономерности экономического роста. Й. Шумпетером вводится различие «приспособительской реакции» и реакции «дестабилизирующей, инновационной, творческой». Автор полагает, что это различие является базисом в проведении отличия homo economicus и homo creativus; homo creativus восстает против созданного природой, - инновация и позволяет через заявленное решение заявить «протест диктату природы». Креативность - средство разрушения стереотипов, творчество по своей природе и сути - подрывная «акция»; подрывы творческой деструкции названы Й. Шумпетером квинтэссенцией капитализма, креативные процессы разрушают наш гештальт ради другого, лучшего. Что касается отношений конкуренций, они важны, по мнению Й. Шумпетера, - не сами по себе, а лишь тогда, когда речь идет в новом говерс, новой технологии, новом источнике снабжения, новом пике организации, - т.е. когда заявляется решающее преимущество в стоимости и качестве, «бьющая не по уровню прибыли и произво- 
дительности компаний, а по самым основам их бытия» [4]. В этом решающем преимуществе и заключена дестабилизирующая, инновационная, творческая реакция homo creativus.

Когнитивное общество пронизано этосом креативности, понимаемым как «преобладающий дух или характер культуры», - эта идея цементирует все рассуждения об обществе знания и П. Друкера, и Й. Шумпетера, Позднее, в 2007 году Р. Флорида в упоминаемой ранее работе «Креативный класс. Люди, которые меняют будущее» излагает морфологическую специфику креативного этоса, назвав черты, вне которых этот этос не может существовать и благодаря которым он обнаруживает и реализует свой потенциал.

Креативность имеет множество параметров и измерений. «Креативность предполагает определенные типы мышления и характера, которые необходимо культивировать как на индивидуальном уровне, так и в обществе, окружающем человека. Соответственно, креативный этос проникает повсюду, от профессиональной культуры до общечеловеческих ценностей и сообществ, изменяя наше представление о себе как об экономических и социальных субъектах, т.е. саму идентичность. В нем отражаются нормы и ценности, которые одновременно питают креативность и помогают усилению ее роли. Сверх того, креативность нуждается в поддерживающей среде, обеспечивающей совокупность стимулов - социальных, культурных и экономических. Поэтому она напрямую связана с развитием новых услолвий труда, стилей жизни, форм общения между людьми и соседскими сообществами, которые, в свою очередь, способствуют творческой деятельности» [3, с.35].

В совокупности характеристик этоса креативности - способность к синтезу, умение рисковать, как и непокидающее креативного человека желание риска. Креативный этос формируется лишь через отход от конформистского прошлого; по своей природе «...творческая деятельность носит откровенно подрывной характер, поскольку она развивает существующие стереотипы мышления и поведения» [3, с.46]. Для креативности неприемлем контекст изоляции, Р. Флорида пишет о результативности мысли, способной к «перекрестному опылению и взаимной стимуляции», что, в свою очередь, возможно лишь через реализацию потребности в самореализации и в среде, формирующей креативность. Фактором, формирующим креативность, Р. Флорида считает присущий среде командный стиль - именно этот стиль, работа в команде играет роль провоцирующего стимула, формирующего креативность.

Отметим вместе с тем то различие, что определяет отношение к креативности П. Друкера и р. Флориды. Если в концепции П. Друкера акцент сделан на знании как доминирующем культурном ресурсе экономики знания, «средство производства», то Р. Флорида акцентирует внимание на креативности как «доминирующем ресурсе социальной жизни», однако именно этот ресурс, порождающий применение знания, способен создавать новое и принципиально социально значимое - инновации, интерпретируемые в шумпетерианских речах в качестве «креативного разрушителя». В классической традиции (М. Боуден, Р. Флорида, Дж. Мокир) понятия «креативность» и «интеллект», являясь проявлением когнитивного потенциала личности, интерпретированы по-разному. Аналитики делают, определяя креативность как свойство нового класса эпохи цивилизации знания, акцент на таких свойствах, присущих креативному классу, как готовность к созданию нового, одновременно и готовность к рискам и ошибкам (последние способны сыграть в перспективе роль фактора-указания), однако то главное, с чем связана проявляемая креативность это способность к синтезу, та «комбинаторная игра», о которой писал А. Эйнштейн. Построение экономики знания (креативной, инновационной экономики) без использования потенциала креативных невозможно. Пока же разрыв численности креативного класса в США и в России определен цифрами 38 млн (это 30\% всех работающих американцев) и 13 млн от общего населения этих сверхдержав, это абсолютная численность представляющих креативные сферы труда, и Россия здесь занимает второе место после США. Ситуация, однако меняется в случае, если принят во внимание процент общей рабочей силы, - место России становится шестнадцатым; это место становится двадцать пятым, если говорить о мировом индексе, формируемом с учетом таких позиций, как талант, технологии, креативность (обозначенные позиции представлены в исследовании Р. Флориды «Креативный класс. Люди, которые меняют будущее»). Что касается доминирующего определения критерия классовых различий, он изменен. В классических определениях доминирующую роль играет отношение к средствам производства (оно определяет и такие признаки класса, как отношения распределения и отношения обмена). Теория креативного класса в качестве критерия использует способность реализации творческих функций. В заключение приведем материал, основанный на сравнении ситуации с численностью креативного класса в 1900 году, 1959 году и, наконец, в 1999 году (нами использованы данные из двух авторитетных источников - «Historical Statistics of the United States» и «2000 Statistical Abstract of the United States»): в 1900 году численность богемы в 100000 человек составляла 266 человек, шестьдесят лет спустя, в 1959 году эта цифра составляла 344,1 человек и еще сорок лет спустя - 899,9 человек на 100000 населения. Что касается сообщества ученых, в 1900 году в 100000 населения насчитывалось 55,2 ученых; в 1950 году число представителей этого креативного класса увеличилось до 410,5 человек на 100000 населения, и уже в 1999 году составило 1821,1 на 100000 населения. 
Хотя, предпочитая определенный стиль жизни, определенный образ жизни, составляющие креативный класс не идентифицируют себя как класс. Профессионал, отличающийся креативными характеристиками, разделяющий принципы креативного этоса, утверждает в этой связи Р. Флорида, относит себя не просто к корпоративным служащим, он считает себя «организационным человеком», частью креативного класса. Отсюда, по мнению Р. Флориды, предпочтение, отдаваемое профессионалами стимулирующей креативной среде, - это города с их системой возможностей и удобств, с их терпимостью к различиям, где проявляется возможность идентифицировать себя с креативным классом. Ведущими центрами креативности для США являются города восточного побережья - Вашингтон, Бостон, Нью-Йорк, районы залива Сан-Франциско, Сиэтла, Остина. Что касается определения класса, в социологической теории класс представлен как совокупность людей, обладающих общими интересами и склонных думать, чувствовать и вести себя сходно, однако эти черты сходства в корне определяются экономической функцией - тем видом работы, который обеспечивает им средства к существованию. При этом социологи говорят о двух группах тех, кто составляет креативный класс: ядро креативного класса, - из научной и технической среды, сфер архитектуры, дизайна, образования, искусства, индустрии развлечений (экономическая, функция входящих в ядро сведена к созданию идей, технологий, креативного содержания, - новых и социально значимых) и креативные специалисты - из сфер бизнеса, финансов, права, здравоохранения [1]. В их компетенции - принятие решений, касающихся сложных задач, для чего нужно обладать независимым стилем мышления, высоким уровнем образования и человеческого капитала. Разделять принципы, на которых формируется творческий этос, - необходимое условие принадлежности к креативному классу.

Трансформационные сдвиги для креативного класса касаются ряда позиций, - это трансформация деятельности, стиля и образа жизни, сферы общения, трансформации оказалась подвержена и система принципов структурирования времени; креативность нашла воплощение в смешении работы и игры, в интенсивной концентрации и расслаблении, в новых принципах структурирования времени. Последнее, в частности, нашло отражение в явлении, обозначенном аналитиками как «фронтальная загрузка» профессиональной карьеры, когда продуктивная креативная занятость не характерна только для опытных, но реализуется молодыми. И если «организационная эпоха» отдавала предпочтение конформизму, в эпоху креативной экономики предпочтение отдано индивидуальности, самореализации через опыт, характерной чертой которого выступает разнообразие, терпимость к различиям, сама же культура являет собой «смесь буржуазных и богемных ценностей» (Д. Брукс). Сам же процесс идентификации для креативной личности уже не связан столь жестко с понятиями, определяющими фундамент существования для личности прошедшей эпохи (профессия, место работы, семейное положение) [2].

Инновационная экономика, определившая ту степень своего интенсивного развития за счет выхода приоритетные позиции знания как доминирующего ресурса общества знания, продемонстрировала небывалую востребованность в креативном классе. За десятилетия XX века численность креативного класса в США выросла более чем в 10 раз, 12\% рабочей силы США отнесены аналитиками к суперкреативному ядру рабочей силы, - а это 15 млн специалистов. Рабочий класс США сегодня составляет около четвертой части всей рабочей силы этой сверхдержавы, в сфере сервиса здесь занято 55 млн человек. Что касается креативного класса, в численности он уступает сфере сервиса, однако он играет роль крупного игрока в экономике США, превосходя класс того «организационного человека», о котором У. Уайт писал в пятидесятые годы. Креативный класс известен такими чертами, как индивидуализм и открытость разнообразию; креативный класс ушел (и ушел достаточно далеко) от гомогенности и конформизма организационной эпохи. Доход нового класса вдвое выше дохода других классов, однако практически никто из представляющих креативный класс не работает, не покидая однажды выбранную компанию. Основанием такого подхода является желание оставаться собой, выполнять интересную работу, находясь рядом с теми, кто разделяет с тобой однажды выбранные ценности и приоритеты.

\section{ЛИТЕРАТУРА}

1. Акофф Р. Планирование будущего корпорации. М.: Прогресс, 1985.

2. Россман В. Мистерия центра: идентичность и организация соц. Пространства в современных и традиционных обществах // Вопросы философии. 2008. № 2. C. 42-57.

3. Флорида Р. Креативный класс: люди, которые меняют будущее. М.: Издат. Дом Классика-XXI, 2007.

4. Шумпетер Й. Теория экономического развития: Исследование предпринимательской прибыли, капитала, кредита, процента и цикла конъюнктуры. М.: Прогресс, 1982.

(c) Кривовяз Наталья Викторовна (awatanchik@yandex.ru).

Журнал «Современная наука: актуальные проблемы теории и практики» 